\title{
RESULTS OF COMPARATIVE ANALYSIS OF FORMATION OF PERSONNEL POTENTIAL OF PHARMACEUTICAL SUPPLY SYSTEMS IN UKRAINE, BELARUS, POLAND, COUNTRIES OF THE CIS AND THE EUROPEAN REGION OF WHO
}

\author{
Alla Kotvitska ${ }^{1}$ \\ alla_kotvitska@ukr.net \\ Daryna Tarasenko ${ }^{1}$ \\ darinka28t@gmail.com \\ ${ }^{I}$ National University of Pharmacy \\ 53 Pushkinska str., Kharkiv, Ukraine, 61002
}

\begin{abstract}
As a result of the radical changes that have taken place in pharmacy at the turn of the century, the role of pharmaceutical workers has acquired a fundamentally new meaning and development in the health care system of the countries. Under these conditions, the issue of forming the human resources of pharmaceutical support systems acquires not only important professional significance, but also acquires socio-economic content for the effective development of the macroeconomic complex of countries as a whole.

The aim. Carrying out a comparative analysis of the process of forming the human resources of pharmaceutical supply systems in Ukraine, Belarus, Poland, the countries of cooperation of the Independent States (CIS) and the European Region countries (ER) of the World Health Organization (WHO).

Materials and methods. The indicators of the total number of graduates-pharmacists, as well as indicators of the number per 100 thousand population in Ukraine, Belarus, Poland, the CIS and ER of WHO during 2000-2013 were studied. These indicators are presented on the European Health Information Portal. («Information and facts»). The authors used historical, information-analytical, analytical-comparative, systemic, logical, hypothetical-deductive and generalizations, as well as mathematical-statistical research methods.

Results. It is established that during 2000-2013 in Ukraine there was a significant increase in the number of graduates of pharmacists from 2.61 to 14.49 people per 100 thousand people. It is proved that Ukraine had the highest rates (\%) of changes in these indicators, compared to other countries. Thus, the average value of the growth rate (\%) of this indicator in Ukraine was $15.0 \%$, in Belarus and the CIS countries $-9.0 \%$, in Poland - 3.0 \%, and in the ER of WHO - $4.0 \%$. It should be noted that in Ukraine, Belarus and Poland there was an unstable nature of changes in the number of graduates of pharmacists, per 100 thousand of us. According to the comparative analysis, it was found that the average value of the analyzed indicator in Ukraine was 5.8 times higher than in Belarus and 2.3 times higher than in Poland. In addition, the corresponding data of Ukraine were 3.1 and 2.6 times higher than similar indicators calculated in the CIS and ER of WHO countries. It is also noteworthy that the decline in Ukraine was characterized only by one year (2010), and amounted to $3.0 \%$.

Conclusions. Against the background of a systematic increase in the number of graduates-pharmacists who received diplomas in higher educational institutions of Ukraine, it is promising to analyze the dynamics of changes in the number of specialists who are actively engaged in professional activities in the pharmaceutical system. Confirming the status of a pharmaceutical country, in our opinion, Ukraine should form a socially oriented profile of the human resources potential of the health care system among the ER countries of WHO.
\end{abstract}

Keywords: graduates-pharmacists, staff of the system of pharmaceutical support of the population, personnel potential, system of pharmaceutical support of the population, pharmacist.

DOI: $10.21303 / 2504-5679.2021 .001566$

\section{Introduction}

In recent years, the public health system has undergone significant changes that have affected virtually all areas of activity. Particularly acute influence of various external factors was felt by socially-oriented industries, namely the system of pharmaceutical supply and its important component the market of drugs and other products of the pharmaceutical range [1,2]. The introduction of socially oriented forms and methods of pharmaceutical services is currently considered in the vast majority 
of countries as a priority for the development of national health care systems [3, 4]. Ukraine is no exception to this list of countries, which since independence in 1991 has undergone a difficult path of development in the direction of health care in general and the pharmaceutical supply system in particular $[5,6]$. The pharmaceutical supply systems of European countries have also undergone a difficult path of development, which at the end of the last century began an active path to the introduction of socially oriented forms and methods of public service and health care reform in general [7, 8].

In the pharmaceutical market, many interests intersect, from legal and purely commercial, to moral, ethical and psychological [9, 10]. Effective implementation of the social burden, which is increasing every year in the pharmaceutical market, requires employees of pharmacies to constantly acquire new knowledge and skills $[11,12]$. In addition, as a result of the radical changes that have taken place in pharmacy at the turn of the century, the role of pharmaceutical workers has acquired a fundamentally new meaning and vision of development in the health care system [13, 14]. At present, pharmacies and pharmaceutical workers are no longer considered as passive subjects of relations in the health care system $[15,16]$. Every year their role is transformed, and professional and social influence increases $[13,17]$. In turn, the level of social influence on the pharmaceutical supply system increases every year, and the drug market forms new requirements for professionals in a wide range of their competencies for practical skills [18].

Against the background of intensified development of European integration processes in the country, the issue of forming human resources of such an important, from a socio-economic point of view of the macroeconomic complex of the state, which is the system of pharmaceutical supply, is relevant. This determined the aim of our research.

The aim. Identification of the main characteristics and development trends of the process of forming the human resources system of the pharmaceutical system in Ukraine, Belarus, Poland, the countries of cooperation of the Independent States (CIS) and the European Region (ER) of the World Health Organization (WHO).

\section{Materials and methods}

The objects of the study were data, presented on the European Health Information Portal («Information and Facts»). The indicators of the total number of graduates-pharmacists and in terms of 100 thousand population in Ukraine, Belarus, Poland, the CIS countries and the ER of WHO during 2000-2013 were studied.

The content of the indicator «number of pharmaceutical graduates in terms of 100 thousand population» according to the European Health Information Portal is as follows:

- It is a part of the general indicator with the indicator of the name «Pharmacists engaged in practical professional activity, all». Number of pharmaceutical graduates per 100,000 population.

- The indicator is presented on the site in accordance with the code: grad.pharm.rate.

- Defined as the total number of students who received a diploma with a formal qualification in the relevant year.

- Link to relevant WHO data: https://gateway.euro.who.int/ru/indicators/hlthres_154-pharmacists-graduates-per-100-000/. Data are presented at the end of the calendar year. The last update of WHO data took place on September 20, 2016.

For the convenience of the analysis, the number of pharmaceutical graduates per 100 thousand population received a symbol - indicator A. The analysis of the dynamics of change was conducted from 2000 to 2013. It should be noted that the European database on human and technical resources of health care (HlthRes- DB) contains statistics on 200 indicators from 53 countries [19]. The latest data presented on the information portal dates back to 2013-2014.

An important step in conducting these studies was to determine the group of reference countries. In the process of selecting countries for comparison, we used the following statements:

- the election of a country which, according to the parameters of historical and socio-economic development, has for a long time been in the same conditions as Ukraine;

- the need to take into account the intensification of European integration guidelines for the development of the country in the medium and long term, which is declared in numerous regulations $[5-7,20]$. 
Thus, we have selected for comparison such countries and associations as Belarus, Poland, the CIS countries and the ER countries of WHO.

Methods for analyzing the dynamics of interval complete series were used. As you know, in complete series, dates or periods follow each other at regular intervals. We calculated growth rates $(\%)$ and growth $(\%)$, as well as chain values of growth/decrease coefficients $\left(k_{k n+1)}\right.$. In addition to chain indicators, we also calculated the basic (comparison to the first period in time) data to the indicators of 2000. The range of fluctuations of indicators was determined using the variation of the data $\left(R=N_{\max }-N_{\min }\right)$, as well as in \%, as the ratio of the range of fluctuations to $N_{\min }$ [19].

All required indicators were processed using the standard statistical analysis package Statistica (version 12.0, StatSoft, Tulsa, USA). In statistical calculations, the value of $p<0.05$ was considered statistically significant.

Historical, information-analytical, analytical-comparative, systemic, logical, hypotheticaldeductive and generalizations, as well as mathematical-statistical research methods are used.

\section{Research results}

According to the results of research, we can say the following. In 2000, the indicator A in Ukraine, Poland and ER countries of WHO ranged from 2.61 to 2.63 people per 100 thousand people. The lowest value of indicator A was observed in Belarus, and in general in the CIS countries it was equal to 1.72 people per 100 thousand people. That is, Ukraine at the beginning of the observation period had the closest to European values indicator $A$. Later, the dynamics of this indicator showed an increase in a significant range of values.

Thus, in Ukraine, a systematic increase in data from 2.61 to 14.49 people per 100 thousand people observed during 2000 and 2013 and increased 5.6 times. For comparison, in Belarus this indicator increased only 2.7 times, in Poland - 1.3 times, in the CIS countries as a whole -2.8 times, and in the ER countries of WHO - 1.6 times.

The variation range of domestic indicators $\mathrm{A}$ was equal to 11.88 or $455.2 \%$. The highest growth rates $(+35.0 \%)$ of indicators A in Ukraine are observed in 2005 (indicator A increased from 5.89 to 7.93 persons per 100 thousand people).

It should be noted that in Ukraine every year there was an increase in indicator A at different rates (\%), the only exception is the data for 2010 . Thus, this year the indicator A, compared to the previous 2009 decreased by $3.0 \%$. In general, it should be noted that in comparison with other countries, Ukraine was characterized by the highest values of indicators A for all years of the study (except for data on Belarus in 2001 and the CIS countries in 2002), as well as growth rates (\%) data. The latter ranged from $3.0 \%$ to $35.0 \%$, but in general, the dynamics of indicators was unstable and can be described as «wavy».

It is noteworthy that in Belarus, indicator A had the lowest data compared to other countries. Thus, the indicator A ranged in the range of values from 0.69 (2000) to 2.02 people per 100 thousand people (2010), i.e. the variation range was equal to 1.33 or $192.8 \%$. The maximum growth of indicators was typical for $2001(+52.0 \%)$. At the same time, a decrease in data compared to the previous period was observed in 2004 (-5.0\%), 2009 (-11.0\%), $2011(-7.0 \%)$ and in $2013(-1.0 \%)$. That is, it can be argued that in Belarus, the dynamics of indicator A was extremely unstable in retrospect. The results of the comparative analysis are shown in Table $\mathbf{1}$.

In Poland, the indicator A ranged from 2.55 (2005) to 3.37 people per 100 thousand people (2011). The variational range was only 0.82 or in $\%$ it was $32.16 \%$. For example, for Ukraine, a similar statistic was $455.17 \%$. The maximum increase $(+20.0 \%)$ was observed in Poland according to 2006 data, and a decrease was observed in $2001(-1.0 \%), 2005(-10.0 \%) .2009(-1.0 \%)$, $2010(-3.0 \%), 2012(-6.0 \%)$. That is, it can be argued that in Poland, as in Belarus, there was an unstable nature of changes in indicators $\mathrm{A}$ in retrospect.

Analyzing the data in Table 1, we can say that the indicator A in the CIS countries ranged from 1.72 (2000) to 4.90 people per 100 thousand people (2013), i. e. the range of variation was 3.18 or $184.9 \%$. Maximum growth $(+45.0 \%)$ indicator A according to the data of 2002 . Thus, this indicator increased from 1.88 to 2.72 persons per 100 thousand people. The decline in data relative to previous values was observed in $2004(-1.0 \%)$ and $2010(-4.0 \%)$. 
Table 1

The results of a comparative analysis of changes in indicators $\mathrm{A}$ in the dynamics of years

\begin{tabular}{|c|c|c|c|c|c|c|c|c|c|c|}
\hline \multirow{3}{*}{ Years } & \multicolumn{10}{|c|}{ Analysis indicator $\mathbf{A}$} \\
\hline & \multicolumn{2}{|c|}{ Ukraine } & \multicolumn{2}{|c|}{ Belarus } & \multicolumn{2}{|c|}{ CIS countries } & \multicolumn{2}{|c|}{ Poland } & \multicolumn{2}{|c|}{ ER countries of WHO } \\
\hline & $A_{1}$ & $k_{1+n}$ & $A_{2}$ & $k_{1+n}$ & $A_{3}$ & $k_{1+n}$ & $A_{4}$ & $k_{1+n}$ & $A_{5}$ & $k_{1+n}$ \\
\hline 2000 & 2.61 & - & 0.69 & - & 1.72 & - & 2.61 & - & 2.63 & - \\
\hline 2001 & 2.85 & 1.09 & 1.05 & 1.52 & 1.88 & 1.09 & 2.58 & 0.99 & 2.61 & 0.99 \\
\hline 2002 & 3.66 & 1.28 & 1.14 & 1.09 & 2.72 & 1.45 & 2.65 & 1.03 & 2.91 & 1.11 \\
\hline 2003 & 4.72 & 1.29 & 1.52 & 1.33 & 3.55 & 1.31 & 2.83 & 1.07 & 3.44 & 1.18 \\
\hline 2004 & 5.89 & 1.25 & 1.45 & 0.95 & 3.50 & 0.99 & $-*$ & -* & 3.24 & 0.94 \\
\hline 2005 & 7.93 & 1.35 & 1.47 & 1.01 & 4.35 & 1.24 & 2.55 & 0.90 & 3.38 & 1.04 \\
\hline 2006 & 9.56 & 1.21 & 1.55 & 1.05 & 4.42 & 1.02 & 3.05 & 1.20 & 3.55 & 1.05 \\
\hline 2007 & 10.72 & 1.12 & 1.68 & 1.08 & 4.81 & 1.09 & 3.11 & 1.02 & 3.59 & 1.01 \\
\hline 2008 & 12.94 & 1.21 & -* $^{*}$ & _* & 4.85 & 1.01 & 3.29 & 1.06 & 3.71 & 1.03 \\
\hline 2009 & 12.94 & 1.00 & 1.50 & 0.89 & 4.85 & 1.00 & 3.24 & 0.99 & 3.84 & 1.04 \\
\hline 2010 & 12.54 & 0.97 & 2.02 & 1.35 & 4.65 & 0.96 & 3.13 & 0.97 & 3.87 & 1.01 \\
\hline 2011 & 12.91 & 1.03 & 1.87 & 0.93 & 4.65 & 1.00 & 3.37 & 1.08 & 3.9 & 1.01 \\
\hline 2012 & 13.26 & 1.03 & 1.87 & 1.00 & 4.77 & 1.03 & 3.17 & 0.94 & 4.19 & 1.07 \\
\hline 2013 & 14.49 & 1.09 & 1.86 & 0.99 & 4.90 & 1.03 & 3.36 & 1.06 & 4.27 & 1.02 \\
\hline Av. val. & 9.07 & 1.15 & 1.57 & 1.09 & 3.97 & 1.09 & 2.91 & 1.03 & 3.51 & 1.04 \\
\hline
\end{tabular}

Note: *-data on the site are missing

In the ER countries of $\mathrm{WHO}$, indicator A was measured in the range of values from 2.61 (2002) to 4.27 persons per 100 thousand people (2013). Thus, the magnitude of the variation of the indicators was equal to 1.66 or $63.60 \%$. The highest growth rate was typical for 2003 , namely $+18.0 \%$. In turn, a slight drop in data was typical for 2001 (-1.0\%) and $2004(-6.0 \%)$. Thus, it can be argued that in the CIS and ER countries of the WHO in comparison with Ukraine, Belarus and Poland, there was a more stable dynamics of changes in indicators A.

The next stage of our research was a comparative analysis of the average values of indicator A and the rate (\%) of its growth by country. It was found that the average value of growth rates (\%) of indicators A in Ukraine was $15.0 \%$, in Belarus and the CIS countries - $9.0 \%$, Poland - $3.0 \%$, and in the ER countries of $\mathrm{WHO}-4.0 \%$. As can be seen, the domestic indicators characterizing the dynamics of changes in the analyzed data are 1.7 times higher than in Belarus and the CIS countries, and 5.0 and 3.8 times higher than the corresponding data in Poland and the ER countries of WHO. The results of the analysis of average indicators A by group of reference countries are presented in Fig. 1.

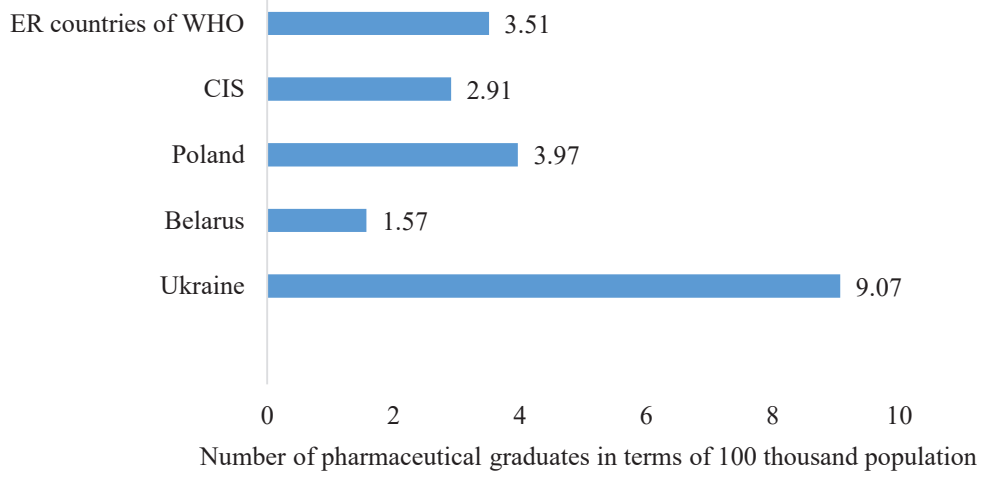

Fig. 1. The results of a comparative analysis of the average values of indicator $A$ by group of reference countries 
According to the results of the analysis, the average value of indicator A in Ukraine is 5.8 times higher than in Belarus and 2.3 times higher than in Poland. Comparing the domestic average data with the group of CIS and ER countries of WHO, it can also be stated that the Ukrainian data were 3.1 and 2.6 higher than similar data in the CIS and ER countries of WHO, respectively.

\section{Discussion of results}

Based on the generalization of the results of the research, it can be stated that Ukraine has consistently held a leading position in the number of graduates-pharmacists (indicator $A$ ). During the studied years in Ukraine, there was a steady increase in the number of graduates who received appropriately diplomas from pharmacists, which was characterized by incomparably higher growth rates (\%) compared to other countries included in the analysis. The dynamics of the number of graduates (pharmacists, pharmacists) who received diplomas in Ukraine, Belarus and Poland, according to the European Health Information Portal WHO is presented in Fig. 2. It should be noted that these data on the CIS and ER countries of WHO, unfortunately, were not available.

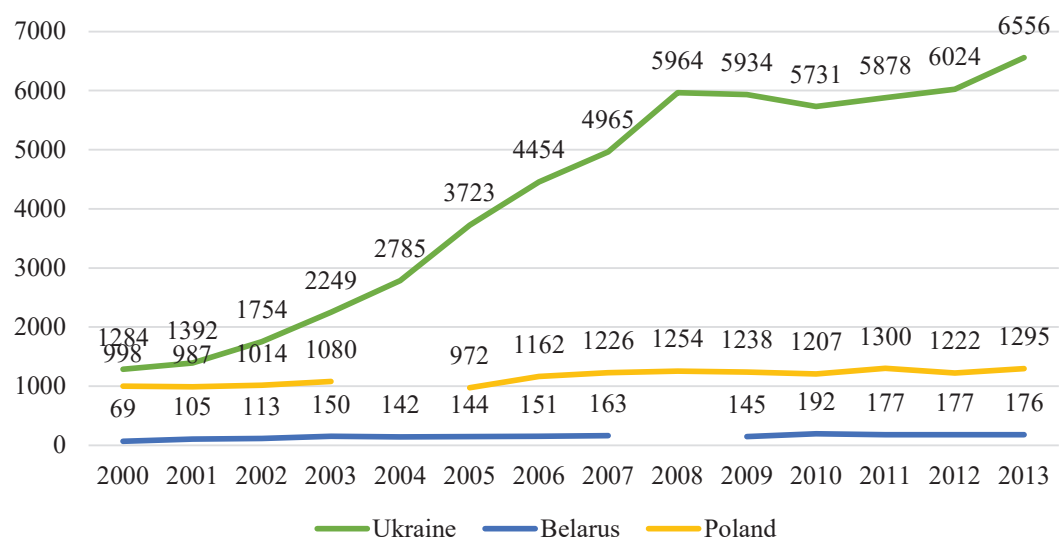

Fig. 2. Analysis of the dynamics of indicators A (total number of graduates) in Ukraine, Belarus and Poland during 2000-2013 according to the WHO

Thus, taking into account the results of the research, it can be argued that Ukraine can reasonably consider itself a pharmaceutical country, especially in the direction of training relevant specialists for the health care system. At the same time, it should be noted that the nature of the changes in the studied indicators is unstable compared to similar data observed in the CIS and ER countries of WHO, which requires further research in this area.

This approach provides an opportunity to qualitatively assess the effectiveness of training future professionals for the pharmaceutical supply system in retrospect.

Study limitations. Carrying out research in the specified direction, it is necessary to note the following restrictions in use of the received results. First, the studies were limited to a certain period of time after which WHO provided country data on the official website of the European Information Portal. It should be noted that this limitation was objective in nature and was taken into account by us in the design of the research. Secondly, given the retrospective nature (2000-2013) of the obtained data, their practical use may currently be limited. Since 2013, significant changes have taken place in the educational space of the reference countries in the direction of training pharmaceutical personnel. Nevertheless, the main trends and the nature of changes in indicators outlined by us allowed, in general, to assess the state of development of the analyzed process.

Prospects for further research. In our opinion, a comparative analysis of the dynamics of changes in indicator $\mathrm{A}$ and the total number of specialists working in pharmacies of various forms of ownership and management in Ukraine is promising. 


\section{Conclusions}

1. On the basis of the conducted researches it is determined that during 2000-2013 in Ukraine there was a significant increase in these indicators of the number of pharmaceutical graduates in terms of 100 thousand population, from 2.61 to 14.49 people per 100 thousand people. That is, at the beginning of the observation period, Ukraine had the closest to European values indicator A, and later its growth had the highest rate (\%) by group of reference countries.

2. It was found that Ukraine had the highest rate of change in indicator A. It was found that the average growth rate (\%) of indicators A in Ukraine was $15.0 \%$, in Belarus and the CIS - $9.0 \%$, Poland $-3.0 \%$, and in the ER countries of WHO $-4.0 \%$.

3 . It is established that the decrease in the relevant indicators, compared to the data of the previous period, was typical for Ukraine only for one year (2010, data drop -3.0\%). For example, in Belarus, a decrease in $A$ compared to previous data was observed for 5 years, in Poland -4 years, and for the CIS and ER countries of WHO - 2 years.

4. Analyzing the dynamics of indicators A, it can be argued that the most stable nature of their changes was characteristic of the CIS and ER countries of WHO.

5. It is proved that the average value of indicator A in Ukraine was 5.8 times higher than in Belarus and 2.3 higher than according to data in Poland. In addition, the corresponding Ukrainian data were 3.1 and 2.6 times higher than similar figures calculated in the CIS and ER countries of WHO.

\section{Conflict of interest}

The authors declare that they have no conflicts of interest.

\section{References}

[1] Samborskyi, O., Slobodyanyuk, M., Panfilova, H., Lebedynets V., Bogdan N. (2019). Analysis of changes in market characteristics of Essential Medicines within the frames of state program of increasing availability of medicines in Ukraine. Journal of Pharmaceutical Sciences and Research, 11 (5), 1679-1686.

[2] Dolovich, L., Austin, Z., Waite, N., Chang, F., Farrell, B., Grindrod, K. et. al. (2018). Pharmacy in the 21st century: Enhancing the impact of the profession of pharmacy on people's lives in the context of health care trends, evidence and policies. Canadian Pharmacists Journal / Revue Des Pharmaciens Du Canada, 152 (1), 45-53. doi: http://doi.org/10.1177/1715163518815717

[3] Tkachenko, N. O., Hromovyk, B. P. (2019). Place and role modeling of social responsibility in professional activity of pharmaceutical specialists. Management, Economics and Quality Assurance in Pharmacy, 2 (58), 28-36. doi: http://doi.org/10.24959/uekj.19.4

[4] Kehrer, J. P., Eberhart, G., Wing, M., Horon, K. (2013). Pharmacy's role in a modern health continuum. Canadian Pharmacists Journal / Revue Des Pharmaciens Du Canada, 146 (6), 321-324. doi: http://doi.org/10.1177/1715163513506370

[5] Hala, L., Panfilova, H. (2019). Analysis of the creation of a modern pharmaceutical support system in ukraine in a retrospective development of the state and civil society relations. Eureka: Health Sciences, 5, 34-43. doi: http://doi.org/10.21303/ 2504-5679.2019.001003

[6] Lekhan, V., Dorit, N. K., Jakubowski, E., Richardson, E. (2015). Reforming the Ukrainian health system at a time of crisis. Eurohealth incorporating Euro Observer, 21 (2), 14-16.

[7] Pogorzeczyk, K., Synoweć, J., Robakowska, M., Ślęzak, D. et. al. (2018). Pharmaceutical markets regulation overview of the selected European Union countries. Wiadomości Lekarskie, 71 (7), 1404-1408.

[8] Fox, A. M., Reich, M. R. (2015). The Politics of Universal Health Coverage in Low- and Middle-Income Countries: A Framework for Evaluation and Action. Journal of Health Politics, Policy and Law, 40 (5), 1023-1060. doi: http://doi.org/10.1215/ 03616878-3161198

[9] Pashkov, V. M. (2003). Pravova kharakterystyka rynku likarskykh zasobiv v Ukraini. Ezhenedelnyk Apteka, 24 (395). Available at: https://www.apteka.ua/article/14184

[10] Etychnyi kodeks farmatsevtychnykh pratsivnykiv Ukrainy (2010). Kharkiv, 12. Available at: https://nuph.edu.ua/wp-content/ uploads/2015/04/etichnij_kodeks_pharm_pratsivnik.pdf

[11] Olasiuk, H. (2017). Competitive Forces on the Ukrainian Pharmaceutical Market: Evaluation Aspects. Journal of Applied Management and Investments, 6 (3), 186-196.

[12] Uzman, N., Kusynova, Z., Manikkath, J., Duggan, C. (2019). Making the profession attractive for our future and young pharmacists, the game changers for primary health care. Journal of Pharmacy Practice and Research, 49 (4), 373-375. doi: http:// doi.org/10.1002/jppr.1602 
[13] Hala, L. (2019) Process model of implementation of Good Pharmacy Practice in the activity of pharmacies of Ukraine. World Science, 1 (10 (50)), 57-61. doi: http://doi.org/10.31435/rsglobal_ws/31102019/6722

[14] Boryshchuk, V. O., Soloviov, O. S., Krasnianska, T. M. et. al. (2015). Doslidzhennia stanu orhanizatsii zabezpechennia naselennia likarskymy zasobamy v roky nezalezhnosti Ukrainy - stanovlennia farmatsevtychnoho rynku. Medychna informatyka ta inzheneriia, 3, 47-53.

[15] Slobodyanyuk, M. M., Samborskyi, O. S. (2018). Theoretical applied approaches to improving sectoral regulation of the process of forming a socially-oriented assortment of medicines in the domestic pharmaceutical market. Management, Economics and Quality Assurance in Pharmacy, 1 (53), 35-46. doi: http://doi.org/10.24959/uekj.18.4

[16] Aleshko, D., Spivak, N. (2017). Protses stanovlennia farmatsevtychnoho sektoru u dii. Available at: https://eba.com.ua/article/ process-formation-pharmaceutical-sector-action Last accessed: 10.11.2020

[17] Glonti, K. (2015). Challenges in specialised and inpatient services in former soviet countries. Eurohealth incorporating Euro Observer, 21 (2), 7-9.

[18] Susharyna, I. V., Nemchenko, A. S., Homenko, V. M. (2017). Identifying of the priority areas for improving of state and public regulation in pharmacy. Pharmaceutical Review, 1, 38-44. doi: http://doi.org/10.11603/2312-0967.2017.1.7529

[19] Fang, J.-Q. (Ed.) (2017). Handbook of Medical Statistics. Sun Yat-Sen University, 837.

[20] National Health Reform Strategy for Ukraine 2015-2020. Ministry of Health of Ukraine. International Renaissance Foundation. Available at: https://healthsag.org.ua/wp-content/uploads/2015/03/Strategiya_Engl_for_inet.pdf Last accessed: 08.11.2020 